\title{
The attitude of blood donors towards the use of their samples and information in biomedical research
}

This article was published in the following Dove Press journal: Journal of Blood Medicine

\author{
Adnan I Al-Hindi' \\ Omar F Khabour ${ }^{2}$ \\ Karem H Alzoubi ${ }^{3}$ \\ Nour A Al-Sawalha ${ }^{3}$ \\ 'Department of Medical Laboratory \\ Sciences, Faculty of Health Sciences, \\ Islamic University of Gaza, Gaza, \\ Palestine; 'Department of Medical \\ Laboratory Sciences, Faculty of \\ Applied Medical Sciences, Jordan \\ University of Science and Technology, \\ Irbid, Jordan; ${ }^{3}$ Department of Clinical \\ Pharmacy, Faculty of Pharmacy, Jordan \\ University of Science and Technology, \\ Irbid, Jordan
}

\begin{abstract}
Introduction: Blood donation is important for saving human life as blood is used in surgeries, blood transfusion and for clinical use. The mission of blood banks can be extended to include medical research. The objective of the study was to determine and assess the attitude of blood donors in Gaza towards the use of their blood samples and medical data for biomedical research and the associated ethical issues.
\end{abstract}

Methods: The study is cross-sectional and questionnaire-based and involved 616 blood donors from the Gaza Strip.

Results: The majority of participants ( $86 \%$ ) showed a positive attitude towards donating blood for medical research, including genetic studies. About two-thirds of participants agreed that informed consent should be taken before conducting medical research on the donated blood. A similar percentage also accepted linking of their health information to the donated blood samples. On the other hand, about $38 \%$ of participants disapproved of sharing of their data with third parties such as health insurance companies and health authorities. Finally, 10\% of participants stated that their future blood donation decision would be affected if they knew that part of their donated blood was to be used in research without taking their permission.

Conclusion: Blood donors in Gaza Strip have a positive attitude toward using their donated blood for medical research. More awareness is required with respect to the importance of informed consent and access to biomedical information.

Keywords: ethics, Gaza, blood, donation, research, attitude

\section{Introduction}

Blood transfusion is a crucial part of any healthcare system. It is a lifesaving approach for several critical conditions such as bleeding disorders, hematological disorders and malignancies. Adequate blood supply can be achieved via blood donations, either as voluntary unpaid donation or recruited paid donation. Donated blood can be used for research purposes if not needed for treatment. Blood banks are attractive for biomedical research studies for the following reasons. First, blood banks are convenient places for the collection of a large sample of well characterized and healthy subjects for genomics and epidemiological screening investigations. ${ }^{1-3}$ Second, the availability of donors' contact information allows for re-contact with participants for additional samples. ${ }^{4}$ Finally, blood donors are expected to have a positive attitude towards voluntary research that requires blood sampling. ${ }^{5,6}$ However, one might argue that the use of donated blood for research purposes might discourage some donors, both regular and prospective, from donation of their blood to blood banks in the future. Therefore, it is important to
Correspondence: Omar F Khabour Department of Medical Laboratory Sciences, Jordan University of Science and Technology, Irbid 22I 10, Jordan Email khabour@just.edu.jo 
investigate the attitudes of blood donors towards the use of their donated blood to blood banks for biomedical research.

In the Gaza Strip, the Central Blood Bank Association was established in 1993 to ensure enough blood supply to public and private hospitals and to avoid blood trading. The blood donated at the central blood bank is used mainly for saving lives and also for biomedical research to a limited extent. Blood for saving lives is obtained through self-motivated donation most of the times and through media advertisement and blood donation campaigns when there is a demand. However, the existence of informed consent, the use of the donated blood in biomedical research and the knowledge of the public about this consent either for surgical operations or research are largely unknown in the Gaza Strip. The aim of the present study was to assess the attitude, knowledge and practice of blood donors in Gaza towards the use of their blood samples and data for biomedical research and the associated ethical issues.

\section{Materials and methods Study population and design}

A cross-sectional study was conducted in the Central Blood Bank of AL-Shifa Hospital in the Gaza Strip from May to July 2017. An anonymous questionnaire was distributed to voluntary blood donors by trained research assistants. Subjects were invited to participate in the study while they were waiting to donate blood at the Central Blood Bank. All donors in the first 2 weeks of June 2017, the period of recruitment, were invited to participate in the study. In Gaza, most blood donors are self-motivated. During periods of high demand, donors are recruited through media advertisements and blood donation campaigns. The percentage of new donors each year is about $10 \%$ of the total number of the current donors.

\section{Instrument description}

The questionnaire was developed in Arabic. The study questionnaire was face validated through review by experts in the study topic, including a researcher, an ethicist, a physician and a socialist. This included testing the validity of the instrument's content to ensure that items in the questionnaire were appropriate for the target construct and assessment objectives within the targeted population. Besides, the study questionnaire was further objectively validated by piloting it among a small number of participants $(n=20)$ before the study. For all items in the questionnaire, the concordance in the answers of the participants in the pilot study was more than $90 \%$. The study was approved by the Helsinki Committee in the Palestinian Ministry of
Health. Blood donors were included in the study only after they were fully informed, agreed to participate and signed the informed consent. For the two participants who were 17 years old, the consent was also signed by their guardians. The response rate was $83 \%$.

Each participant was asked to answer 30 questions that covered demographics and socioeconomic characteristics, experience with blood donation, knowledge and attitude towards blood donation related issues. The questionnaire is available with the corresponding author and will be provided upon request.

\section{Statistical analysis}

Categorical variables were presented as numbers and percentages. The differences in the answers to the questionnaire were examined using the chi-squared $\left(\chi^{2}\right)$ test. The multinominal logistic regression test was used to determine the factors (including age, gender, education, occupation, marital status and income) that are independently associated with the knowledge of and attitude towards blood donation related issues. All variables with $P \leq 0.05$ in univariable analysis were included in the multinominal logistic regression test. The significance level was considered at $P<0.05$. Data were analyzed using the Statistical Package for Social Sciences (SPSS, Inc., Chicago, IL, USA) version 20.

\section{Results}

\section{Demographics and socioeconomic characteristics of blood donors}

A total of 616 blood donors volunteered to participate in the study. Around $74 \%$ of the participants were $<25$ years, $87.5 \%$ of were males, around $68 \%$ were workers, $52 \%$ had university education, $53 \%$ were single and $58 \%$ had medium income (Table 1).

\section{Practice, attitude and knowledge of participants about research on donated blood}

About $30 \%$ of the participants had donated blood at least three times in the last 5 years (Table 2). Only $23 \%$ volunteered for health-related research and about $86 \%$ showed medium-to-high willingness in participating in healthrelated research. However, about $10 \%$ of participants stated that their future blood donation would be affected if they knew that part of their donated blood was used in research. The majority ( $>85 \%$ ) of participants agreed to the use their donated blood in medical research including investigation of genetic diseases (Table 2). 
Table I Demographics and socioeconomic characteristics of participants $(n=616)$

\begin{tabular}{ll}
\hline Characteristic & Number of participants (\%) \\
\hline Age (years) & $456(74.0)$ \\
I7-25 y & $110(17.9)$ \\
$26-35$ y & $28(4.5)$ \\
$36-45$ y & $22(3.6)$ \\
$>45 y$ & \\
Gender & $539(87.5)$ \\
Male & $77(12.5)$ \\
Female & \\
Occupation & $189(68.2)$ \\
Employed & $196(31.8)$ \\
Unemployed & \\
Education & $71(11.5)$ \\
Less than GSSE & $125(20.3)$ \\
GSSE & $59(9.6)$ \\
College & $32 I(52.1)$ \\
University & $40(6.5)$ \\
Masters degree or doctorate & \\
Marital status & $324(52.6)$ \\
Single & $286(46.4)$ \\
Married & $6(1)$ \\
Divorced & $237(38.5)$ \\
Income level & $354(57.5)$ \\
Low & $25(4.1)$ \\
Medium & \\
High &
\end{tabular}

Notes: aPercentage values were calculated based on the total number of participants. Abbreviation: GSSE, General Secondary School Education.

\section{Participants' opinion about biomedical research on donated blood}

The majority of participants (64\%) agreed that an informed consent should be provided before conducting medical research on the donated blood. A similar percentage (64.5\%) accepted linking of their health information to the donated blood sample to be used for biomedical research. Further, about $70 \%$ agreed that there was a great need for donated blood samples for conducting biomedical research and this would assist in developing medications for genetic and infectious diseases. However, about $38 \%$ disagreed on the blood test results being given to a third party such as health insurance companies and health authorities. (Table 3)

\section{Factors affecting participants' opinion about biomedical research on donated blood}

The results of univariable analysis showed that age affected the participant's opinion about the necessity of an informed consent for conducting medical research on the blood donated to the blood bank. Among other factors, only gender affected the opinion of participants on the importance of medical research on blood samples for the development of medications for infectious and genetic diseases Table 4). In addition, gender, education, marital status and income level affected the participants' opinion about the test results of the donated blood being given to a third party such as health insurance companies and health authorities. Moreover, age, gender and occupation affected the response of participants to the question that part of the donated blood could be used for research and it should not be linked to donor's health information Table 4).

Results of multinominal logistic regression are shown in Table 5 (only questions and factors that showed significant $P$-values are included in this table). Male participants, as compared to female participants, were more likely to be unsure about the benefits of medical research on donated blood samples in assisting the development of medications for infectious diseases. In addition, employed, rather than unemployed participants, were more likely to agree that part of the donated blood could be used in scientific research, but should not be linked to donor's health information.

\section{Discussion}

The attitude of blood donors in the Gaza Strip towards using their donated blood for medical research was assessed in this study by using several statements that are related to the potential use of donated blood in research. Overall, the majority of the participants were willing to let their donated blood be used towards medical research. In comparison, blood donors in a Danish study believed that the use of their donated blood for medical research would expand the benefits of donation to include enhancement of scientific knowledge and public health. ${ }^{4} \mathrm{~A}$ combination of blood banking and bio-banking for medical research has been successfully established in Bovaria, Italy. ${ }^{7}$ The level of willingness to donate blood was consistent with those in previous studies that were conducted in Tunisia, ${ }^{8}$ western countries, ${ }^{9}, 10$ and Africa. ${ }^{11}$ The motivation behind the willingness of the study participants to be engaged in medical research was their confidence that medical research was beneficial to both society and individuals, where medications for genetic and infectious diseases could be developed and hence provide protection to the society. However, and compared to females, males were less sure about the importance of medical research in the development of medications for infectious diseases. This could be due to type I error as the number of females who participated in the study was low. 
Table 2 Practice, attitude and knowledge of participants about blood donation and research on donated blood $(n=6 \mid 6)$

\begin{tabular}{|c|c|}
\hline Characteristic & Number of participants (\%) \\
\hline \multicolumn{2}{|c|}{ The number of blood donations in the last five years } \\
\hline Zero & $37(6.0)$ \\
\hline Once & $24 I(39.1)$ \\
\hline Twice & $154(25.0)$ \\
\hline$\leq$ Three times & $184(29.9)$ \\
\hline \multicolumn{2}{|c|}{ Previous participation in health-related research } \\
\hline Yes & 140 (22.7) \\
\hline No & $476(77.3)$ \\
\hline \multicolumn{2}{|c|}{ Assessment of personal knowledge of blood diseases } \\
\hline High & $107(17.4)$ \\
\hline Medium & $297(48.2)$ \\
\hline Low & $212(34.4)$ \\
\hline \multirow{2}{*}{\multicolumn{2}{|c|}{$\begin{array}{l}\text { If you know that part of your donated blood to the blood bank is used in } \\
\text { research, will this affect your future blood donation? }\end{array}$}} \\
\hline & \\
\hline Yes & $60(9.7)$ \\
\hline No & $397(64.4)$ \\
\hline Not sure & $159(25.8)$ \\
\hline \multicolumn{2}{|c|}{ The level of willingness to participate in medical research } \\
\hline High & $225(36.5)$ \\
\hline Medium & $305(49.5)$ \\
\hline Low & $86(14.0)$ \\
\hline \multicolumn{2}{|c|}{ Do you agree to use a sample of your donated blood in medical research? } \\
\hline Yes & $549(89.1)$ \\
\hline No & $67(10.9)$ \\
\hline \multicolumn{2}{|c|}{ Do you agree to use a sample of your donated blood in research related } \\
\hline \multicolumn{2}{|c|}{ genetic diseases? } \\
\hline Yes & $528(85.7)$ \\
\hline No & $88(14.3)$ \\
\hline \multicolumn{2}{|c|}{ How confident you are that scientific research in your area is beneficial } \\
\hline \multicolumn{2}{|c|}{ to both society and individuals } \\
\hline High & $217(35.2)$ \\
\hline Medium & $296(48.1)$ \\
\hline Low & $103(16.7)$ \\
\hline \multicolumn{2}{|c|}{ From your perspective, the likelihood that the individual will be harmed } \\
\hline \multicolumn{2}{|c|}{ by participating in health related scientific studies } \\
\hline High & $98(15.9)$ \\
\hline Medium & $220(35.7)$ \\
\hline Low & $298(48.4)$ \\
\hline \multicolumn{2}{|c|}{ Blood donation is related to customs, traditions and religion } \\
\hline Strongly agree & $154(25.0)$ \\
\hline Agree & $237(38.5)$ \\
\hline Not sure & $120(19.5)$ \\
\hline Disagree & $73(11.9)$ \\
\hline Strongly disagree & $32(5.2)$ \\
\hline
\end{tabular}

Note: apercentage values were calculated based on the total number of participants.

Informed consent is an essential aspect of ethical codes and regulations for human subjects to be enrolled in research. ${ }^{12}$ The goal of informed consent is to provide detailed information that is sufficient for the potential subject to decide whether to enroll in the study. ${ }^{13}$ More than half of study participants (65\%) felt that informed consent was required for conducting any medical research on the blood donated to the blood bank. Abou Zeid et al reported that only $44 \%$ of the studied Egyptian population felt that informed consent should provide the participant with the option of having their blood samples stored for future research. ${ }^{14} \mathrm{~A}$ previous study from Jordan showed that a good fraction of participants think that informed consent is not needed for donation of samples to biobanks. ${ }^{15}$ This highlights the importance of enhancing 
Table 3 Participants' opinion about biomedical research on donated blood $(n=6 \mid 6)$

\begin{tabular}{|c|c|}
\hline Statement & $\mathbf{N}(\%)^{a}$ \\
\hline \multicolumn{2}{|c|}{ Prior informed consent is required for } \\
\hline \multicolumn{2}{|c|}{ conducting medical research on the } \\
\hline \multicolumn{2}{|c|}{ donated blood to the blood bank } \\
\hline Yes & $399(64.8)$ \\
\hline No & $217(35.2)$ \\
\hline \multicolumn{2}{|c|}{ Medical research on the donated blood } \\
\hline \multicolumn{2}{|c|}{ samples will assist in the development } \\
\hline \multicolumn{2}{|c|}{ of medications for genetic diseases } \\
\hline Strongly agree & $192(31.2)$ \\
\hline Agree & $285(46.3)$ \\
\hline Not sure & $117(19.0)$ \\
\hline Disagree & $13(2.1)$ \\
\hline Strongly disagree & $9(1.5)$ \\
\hline \multicolumn{2}{|c|}{ Medical research on the donated blood } \\
\hline \multicolumn{2}{|c|}{ samples will assist in the development } \\
\hline \multicolumn{2}{|c|}{ of medications for infectious diseases } \\
\hline Strongly agree & $198(32.1)$ \\
\hline Agree & $294(47.7)$ \\
\hline Not sure & $102(16.6)$ \\
\hline Disagree & $14(2.3)$ \\
\hline Strongly disagree & $8(1.3)$ \\
\hline \multirow{2}{*}{\multicolumn{2}{|c|}{$\begin{array}{l}\text { There is a need for the donated blood } \\
\text { samples for biomedical research }\end{array}$}} \\
\hline & \\
\hline Strongly agree & $157(25.5)$ \\
\hline Agree & $319(51.8)$ \\
\hline Not sure & $113(18.3)$ \\
\hline Disagree & $21(3.4)$ \\
\hline Strongly disagree & $6(1.0)$ \\
\hline \multirow{2}{*}{\multicolumn{2}{|c|}{$\begin{array}{l}\text { Society needs medical research for } \\
\text { diseases protection purposes }\end{array}$}} \\
\hline & \\
\hline Strongly agree & $266(43.2)$ \\
\hline Agree & $277(45.0)$ \\
\hline Not sure & $54(8.8)$ \\
\hline Disagree & $10(1.6)$ \\
\hline Strongly disagree & $9(1.5)$ \\
\hline \multicolumn{2}{|c|}{ If you agree to use a sample of your } \\
\hline \multicolumn{2}{|c|}{ donated blood scientific research, do you } \\
\hline \multicolumn{2}{|c|}{ want to receive the results of the test } \\
\hline Yes & $54 \mid(87.8)$ \\
\hline No & $75(12.2)$ \\
\hline \multicolumn{2}{|c|}{ Receiving the test results of the } \\
\hline \multicolumn{2}{|c|}{ donated blood by a third party, not a } \\
\hline \multicolumn{2}{|c|}{ member of the research team } \\
\hline Strongly agree & $83(13.5)$ \\
\hline Agree & $193(31.3)$ \\
\hline Not sure & $107(17.4)$ \\
\hline Disagree & $|3|(2 \mid .3)$ \\
\hline Strongly disagree & $102(16.6)$ \\
\hline \multicolumn{2}{|c|}{ Do you accept linking your health } \\
\hline \multicolumn{2}{|c|}{ information to the donated blood } \\
\hline \multicolumn{2}{|c|}{ sample for research purposes } \\
\hline Yes & $397(64.5)$ \\
\hline No & $219(35.5)$ \\
\hline
\end{tabular}

Note: apercentage values were calculated based on the total number of participants.
Table 4 Univariable analysis of factors affecting participants' opinion about biomedical research on donated blood

\begin{tabular}{|c|c|}
\hline Statement & $P$-values ${ }^{\text {a }}$ \\
\hline \multicolumn{2}{|c|}{ Prior informed consent is required for } \\
\hline \multicolumn{2}{|c|}{ conducting medical research on the } \\
\hline \multicolumn{2}{|c|}{ donated blood to the blood bank } \\
\hline Age & 0.001 \\
\hline \multicolumn{2}{|c|}{ Medical research on the donated blood } \\
\hline \multicolumn{2}{|c|}{ samples will assist in the development } \\
\hline \multicolumn{2}{|c|}{ of medications for genetic diseases } \\
\hline Gender & 0.008 \\
\hline \multicolumn{2}{|c|}{ Medical research on the donated blood } \\
\hline \multicolumn{2}{|c|}{ samples will assist in the development } \\
\hline \multicolumn{2}{|c|}{ of medications for infectious diseases } \\
\hline Gender & 0.008 \\
\hline \multicolumn{2}{|c|}{ Receiving the test results of the donated } \\
\hline \multicolumn{2}{|c|}{$\begin{array}{l}\text { blood by a third party, not a member of } \\
\text { the research team }\end{array}$} \\
\hline Gender & 0.004 \\
\hline Education & 0.002 \\
\hline Marital status & $<0.001$ \\
\hline Income level & 0.005 \\
\hline \multicolumn{2}{|c|}{$\begin{array}{l}\text { Which of the following models you are } \\
\text { supporting? }\end{array}$} \\
\hline \multirow{2}{*}{\multicolumn{2}{|c|}{$\begin{array}{l}\text { Part of the donated blood should not be } \\
\text { used in scientific research }\end{array}$}} \\
\hline & used in scientific research \\
\hline Income level & 0.005 \\
\hline \multicolumn{2}{|c|}{$\begin{array}{l}\text { Part of the donated blood can be used in } \\
\text { scientific research but should not linked }\end{array}$} \\
\hline \multicolumn{2}{|c|}{ to donor's health information } \\
\hline Age & 0.009 \\
\hline Gender & 0.036 \\
\hline Occupation & 0.023 \\
\hline
\end{tabular}

Note: ${ }^{a} P \leq 0.05$ is statistically significant.

awareness about the importance of the consent process in Arabic populations. In two studies from the US, about $90 \%$ of the blood donors insisted on the importance of having their permission before the leftover of donated blood samples could be used for medical research. ${ }^{6,16}$

The majority of the study participants $(88 \%)$ wanted to know the results of the tests that were conducted on their donated blood samples. This is consistent with the previous findings of Abou-Zeid et al among the Egyptian population. ${ }^{14}$ Wendler and Emanuel found that the majority (89\%) of study participants in the USA requested that they be informed about the results of tests on their stored biological samples. ${ }^{17}$ However, about $38 \%$ of study participants did not agree with the test results being given to a third party such as health insur- 
Table 5 Multinominal regression analysis of factors affecting participants' opinion about biomedical research on donated blood

\begin{tabular}{|c|c|c|c|}
\hline Statement & OR & $95 \% \mathrm{Cl}$ & $P$-values \\
\hline \multicolumn{4}{|c|}{ Medical research on the donated blood samples will assist in } \\
\hline \multicolumn{4}{|c|}{ the development of medications for infectious diseases } \\
\hline \multicolumn{4}{|c|}{ Not sure } \\
\hline \multicolumn{4}{|l|}{ Gender } \\
\hline Male & 6.47 & $1.03-40.53$ & 0.05 \\
\hline Female & Reference group & & \\
\hline \multicolumn{4}{|c|}{ Receiving the test results of the donated blood by a third } \\
\hline \multicolumn{4}{|c|}{ party, not a member of the research team } \\
\hline \multicolumn{4}{|c|}{ Disagree } \\
\hline \multicolumn{4}{|l|}{ Income level } \\
\hline Low & 6.41 & $0.7 I-57.56$ & 0.097 \\
\hline Medium & 11.86 & $1.36-103.4$ & $0.025^{*}$ \\
\hline High & Ref & & \\
\hline \multicolumn{4}{|c|}{ Which of the following models you are supporting? } \\
\hline \multicolumn{4}{|c|}{ Part of the donated blood can be used in scientific research } \\
\hline \multicolumn{4}{|c|}{ but should not linked to donor's health information } \\
\hline \multicolumn{4}{|c|}{ Occupation } \\
\hline Employee & 1.16 & $0.75-1.86$ & 0.47 \\
\hline Un-employed & Ref & & \\
\hline
\end{tabular}

Note: a $P \leq 0.05$ is statistically significant.

ance companies and health authorities. This underlines the importance of donor's privacy and confidentiality and raises a concern about the possible misuse of information. ${ }^{18,19}$ Participants with low and medium levels of income and high education were more likely to disagree on the third party principle.

About $27 \%$ of participants stated that part of the donated blood could be used in scientific research but should not be linked to the donor's health information. Subjects who were employed were more likely to prefer this than the unemployed. This could be due to the fear of stigma, ${ }^{10}$ loss of job, increased payments of health insurance as well as confidentiality issues. ${ }^{10}$ Kettis-Lindblad et al revealed that the Swedish population was willing to donate blood samples given that it was not linked to their identity. ${ }^{20}$

About $10 \%$ of participants stated that their future blood donation would be affected if they knew that part of their donated blood was used in research. This highlights the importance of the informed consent process as integral to the use of donated blood samples in medical research. In addition, this also highlights the importance of building trust between blood donors and blood banking institutions.

The current study has a number of limitations. The study questionnaire was focused on blood samples, whereas patients might have different opinions regarding research that involves other biological samples and fluids. However, on the positive side, the current study involved variety of age groups, a large number of participants and subjects with diverse socioeconomic status.

In conclusion, the current study showed that the majority of blood donors in the Gaza Strip have a positive attitude towards using their donated blood for medical research. Most participants agreed that informed consent should be provided before conducting medical research on donated blood samples. In addition, subjects who were employed, rather than unemployed, were more likely to agree that part of the donated blood could be used for medical research but should not linked to donor's health information.

\section{Acknowledgment}

This project was carried out as part of "The Research Ethics Education Program in Jordan" and has been supported by National Institute of Health (grant no. 1R25TW010026-01).

\section{Disclosure}

The authors report no conflicts of interest in this work.

\section{References}

1. Abadi A, Alyass A, Robiou du Pont S, et al. Penetrance of polygenic obesity susceptibility loci across the body mass index distribution. $\mathrm{Am}$ J Hum Genet. 2017;101(6):925-938.

2. Grabarczyk P, Sulkowska E, Gdowska J, et al. Molecular and serological infection marker screening in blood donors indicates high endemicity of hepatitis E virus in Poland. Transfusion. 2018;58(5):1245-1253. 
3. Robinson MR, English G, Moser G, et al. Genotype-covariate interaction effects and the heritability of adult body mass index. Nat Genet. 2017;49(8):1174-1181.

4. Burgdorf KS, Felsted N, Mikkelsen S, et al. Digital questionnaire platform in the Danish Blood Donor Study. Comput Methods Programs Biomed. 2016;135:101-104.

5. Raivola V, Snell K, Pastila S, Helén I, Partanen J. Blood donors' preferences for blood donation for biomedical research. Transfusion. 2018.

6. Rice MS, Custer BS, Hindes DA, et al. Genetic research in the blood bank: acceptability to Northern California donors. Transfusion. 2010;50(9):1951-1958.

7. Zoglmeier C, Martin S, Weinauer F. The Bavarian Red Cross Blood Donor BioBank: the first successful combination of blood donation and biobanking for medical research. Transfusion. 2011;51(5):1121-1122.

8. Bouida W, Grissa MH, Zorgati A, et al. Willingness to participate in health research: Tunisian survey. BMC Med Ethics. 2016;17(1):016-131.

9. Chen DT, Rosenstein DL, Muthappan P, et al. Research with stored biological samples: what do research participants want? Arch Intern Med. 2005;165(6):652-655.

10. Pentz RD, Billot L, Wendler D. Research on stored biological samples: views of African American and White American cancer patients. Am J Med Genet A. 2006;140(7):733-739.

11. Wendler D, Pace C, Talisuna AO, Maiso F, Grady C, Emanuel E. Research on stored biological samples: the views of Ugandans. IRB. 2005;27(2):1-5.
12. The Belmont Report. Ethical principles and guidelines for theprotection of human subjects of research. J Am Coll Dent. 2014;81(3):4-13.

13. Nijhawan LP, Janodia MD, Muddukrishna BS, et al. Informed consent: Issues and challenges. J Adv Pharm Technol Res. 2013;4(3):134-140.

14. Abou-Zeid A, Silverman H, Shehata M, et al. Collection, storage and use of blood samples for future research: views of Egyptian patients expressed in a cross-sectional survey. J Med Ethics. 2010;36(9): 539-547.

15. Ahram M, Othman A, Shahrouri M. Public perception towards biobanking in jordan. Biopreserv Biobank. 2012;10(4):361-365.

16. Scott EA, Schlumpf KS, Mathew SM, et al. Biospecimen repositories: are blood donors willing to participate? Transfusion. 2010;50(9):1943-1950.

17. Wendler D, Emanuel E. The debate over research on stored biological samples: what do sources think? Arch Intern Med. 2002;162(13):1457-1462.

18. Dreyer NA. Accessing third-party data for research: trust me? Trust me not? Pharmacoepidemiol Drug Saf. 2001;10(5):385-388.

19. Godard B, Schmidtke J, Cassiman JJ, Aymé S. Data storage and DNA banking for biomedical research: informed consent, confidentiality, quality issues, ownership, return of benefits. A professional perspective. Eur J Hum Genet. 2003;11 Suppl 2(S2):S88-S122.

20. Kettis-Lindblad A, Ring L, Viberth E, Hansson MG. Genetic research and donation of tissue samples to biobanks. What do potential sample donors in the Swedish general public think? Eur J Public Health 2006;16(4):433-440.
Journal of Blood Medicine

\section{Publish your work in this journal}

The Journal of Blood Medicine is an international, peer-reviewed, open access, online journal publishing laboratory, experimental and clinical aspects of all aspect pertaining to blood based medicine including but not limited to: Transfusion Medicine; Blood collection, Donor issues, Transmittable diseases, and Blood banking logistics; Immunohematology; Artificial and alternative

\section{Dovepress}

blood based therapeutics; Hematology; Biotechnology/nanotechnology of blood related medicine; Legal aspects of blood medicine; Historical perspectives. The manuscript management system is completely online and includes a very quick and fair peer-review system. Visit http://www.dovepress.com/ testimonials.php to read real quotes from published authors. 